\title{
The alkaloid emetine sensitizes ovarian carcinoma cells to cisplatin through downregulation of bcl-xL
}

\author{
QI SUN ${ }^{1}$, SHINGO YOGOSAWA $^{2}$, YOSUKE IIZUMI $^{1}$, TOSHIYUKI SAKAI ${ }^{1}$ and YOSHIHIRO SOWA ${ }^{1}$ \\ ${ }^{1}$ Department of Molecular-Targeting Cancer Prevention, Graduate School of Medical Science, \\ Kyoto Prefectural University of Medicine, Kyoto; ${ }^{2}$ Department of Public Health and \\ Environmental Medicine, The Jikei University School of Medicine, Tokyo, Japan
}

Received August 7, 2014; Accepted September 24, 2014

DOI: $10.3892 /$ ijo.2014.2703

\begin{abstract}
Cisplatin and its platinum derivatives are first-line chemotherapeutic agents in the treatment of ovarian cancer. However, chemoresistance is the leading cause of therapeutic failure and is responsible for the poor overall survival rate. Here, we describe that emetine, a natural alkaloid used as an anti-amoebiasis drug, sensitized ovarian carcinoma cells to apoptosis induced by cisplatin. The single administration of cisplatin or emetine had a weak effect on cell death. However, co-treatment of cisplatin and emetine remarkably induced apoptosis and reduced the colony formation of ovarian carcinoma cells. Moreover, we showed that apoptosis induced by the combination of cisplatin and emetine was dependent on the activation of caspases $-3,-7$ and -8 . As to the mechanism, downregulation of bcl-xL by emetine was shown to be responsible for enhancing the sensitivity of ovarian cancer cells to cisplatin. These findings suggest that the combination of cisplatin and emetine might be a promising treatment for ovarian cancer.
\end{abstract}

\section{Introduction}

Ovarian cancer is the seventh leading cause of female cancerrelated death globally (1). Although cisplatin and its platinum derivative therapies are effective in treating ovarian cancer, most patients exhibit resistance to this type of chemotherapy (2). It was reported that platinum with taxane was effective for ovarian cancer, but the side effects were relatively severe (3). There is thus an urgent need to develop new chemotherapeutic combinations to maximize clinical benefit while minimizing toxicity.

Correspondence to: Professor Toshiyuki Sakai, Department of Molecular-Targeting Cancer Prevention, Graduate School of Medical Science, Kyoto Prefectural University of Medicine, KawaramachiHirokoji, Kamigyo-ku, Kyoto 602-8566, Japan

E-mail: tsakai@koto.kpu-m.ac.jp

Key words: apoptosis, bcl-xL, cisplatin, emetine, ovarian cancer
Emetine is a natural alkaloid derived from Psychotria ipecacuanha that strongly inhibits the synthesis of biomolecules (4). It has been widely used as an anti-amoebiasis drug since the early 1900s (5). Evidence of emetine's effect against tumor cells first came to light in 1918 (6). Following several preclinical studies of its anticancer activity, phase I/II clinical trials using emetine were performed by the NCI in the mid-1970s (7-10). However, emetine as a single agent showed no clinical benefit with several side effects, such as cardiac damage. Since then, emetine has been found to induce apoptosis in various human leukemic cell lines (11-14) and a lung cancer cell line (15). Recently, emetine has been reported to regulate the alternative splicing of bcl-x in breast cancer MCF-7, prostate cancer PC-3, cervical cancer C33 and lung cancer A549 cell lines, with downregulation of anti-apoptotic bcl-xL mRNA and upregulation of pro-apoptotic bcl-xS mRNA (16).

To date, emetine has been indicated to enhance cisplatininduced apoptosis in leukemia cells (17) and bladder cancer cells (18). However, the precise molecular mechanisms remain unclear. In the present study, we investigated the effect of emetine with or without cisplatin on the ovarian cancer cell line SKOV3. We further clarified that downregulation of bcl-xL is responsible for the synergistic effects of emetine and cisplatin.

\section{Materials and methods}

Cell culture. Human ovarian cancer cell line SKOV3 was obtained as a cell line of the NCI-60 from the National Cancer Institute Developmental Therapeutics Program (NCI DTP, Bethesda, MD, USA). SKOV3 cells were maintained in DMEM (Nissui Pharmaceutical, Tokyo, Japan) supplemented with 10\% FBS (PAA Laboratories, Pasching, Austria), 4 mM glutamine (Nacalai Tesque, Kyoto, Japan), $100 \mathrm{U} / \mathrm{ml}$ penicillin (Meiji Seika Pharma, Tokyo, Japan) and $100 \mathrm{mg} / \mathrm{ml}$ streptomycin (Nacalai Tesque). Cell culture was incubated at $37^{\circ} \mathrm{C}$ in a humidified atmosphere of $5 \% \mathrm{CO}_{2}$.

Reagents. Cisplatin (Wako, Osaka, Japan), emetine (Tokyo Chemical Industry, Tokyo, Japan) and zVAD-fmk (R\&D Systems, Minneapolis, MN, USA) were dissolved in DMSO (Nacalai Tesque). 
Cell growth assay. The number of viable cells was measured by a Cell Counting Kit-8 assay (Dojindo, Kumamoto, Japan) according to the manufacturer's instructions. Cells were seeded at a density of 1,500 cells in each well of 96-well plates (Becton-Dickinson, Franklin Lakes, NJ, USA). After culturing for $24 \mathrm{~h}$, cells were treated with DMSO as a control or cisplatin at the indicated concentrations for $72 \mathrm{~h}$. Then, kit reagent WST-8 was added to the medium and incubated for $4 \mathrm{~h}$. The absorbance of the samples at $450 \mathrm{~nm}$ was measured using a multi-plate reader (DS Pharma Biomedical, Osaka, Japan).

Analyses of cell cycle and apoptosis. Cells were incubated with various agents for 24,48 or $72 \mathrm{~h}$, and then harvested by trypsinization. After centrifugation, the cells were suspended in PBS containing 0.1\% Triton X-100 (Nacalai Tesque), $150 \mathrm{mg} / \mathrm{ml}$ RNase A (Sigma, St. Louis, MO, USA) and $25 \mathrm{mg} / \mathrm{ml}$ propidium iodide (Sigma). The stained cells were analyzed using FACSCalibur (Becton-Dickinson). The data were analyzed using Modifit LT software and CellQuest software (Becton-Dickinson).

Protein isolation and western blot analysis. Cells were lysed with a buffer containing $50 \mathrm{mM}$ Tris- $\mathrm{HCl}$ (Nacalai Tesque), 1\% SDS (Nacalai Tesque), $1 \mathrm{mM}$ DTT (Nacalai Tesque), $0.43 \mathrm{mM} 4$-(2-aminoethyl) benzenesulfonyl fluoride hydrochloride (AEBSF) (Wako) and phosphatase inhibitor cocktail (Nacalai Tesque). The lysate was sonicated and centrifuged at $15,000 \mathrm{~g}$ for $20 \mathrm{~min}$ at $4^{\circ} \mathrm{C}$, and the supernatant was then collected. Equal amounts of the protein extract were subjected to SDS-PAGE and transferred to a PVDF membrane (Millipore, Bedford, MA, USA). The following were used as the primary antibody: rabbit anti-human polyclonal antibody bcl-x (Santa Cruz Biotechnology, Santa Cruz, CA, USA), rabbit anti-human monoclonal antibody caspase-3 (Cell Signaling Technology, Beverly, MA, USA), rabbit anti-human monoclonal antibody cleaved-caspase-3 (Cell Signaling Technology), mouse antihuman monoclonal antibody caspase-7 (R\&D Systems), mouse anti-human monoclonal antibody caspase-8 (Medical $\&$ Biological Laboratories, Nagoya, Japan) and anti- $\beta$-actin (Sigma). The signals were detected with a Chemi-lumi One L (Nacalai Tesque) or an Immobilon Western Chemiluminescent HRP Substrate (Millipore).

Colony formation assay. SKOV3 cells were seeded at a density of 250 cells per well in 6-well plates. After incubation for $24 \mathrm{~h}$, cells were treated with cisplatin at $20 \mu \mathrm{M}$ with or without emetine at $2.5 \mu \mathrm{M}$. The medium was then replaced with a fresh one, and the cells were cultured for 10 days. The colonies fixed in $10 \%$ formaldehyde solution (Nacalai Tesque) were stained in crystal violet (Nacalai Tesque), and the number of viable colonies was counted.

Small interfering (si) RNA transfection. Knockdown of bcl-xL was achieved by transfection with small interfering RNA (siRNA) (Invitrogen, Carlsbad, CA, USA), as previously reported (19), using Lipofectamine RNAiMAX (Invitrogen).

Statistical analysis. Data are expressed as mean \pm SD of three determinations. Statistical analysis was performed using

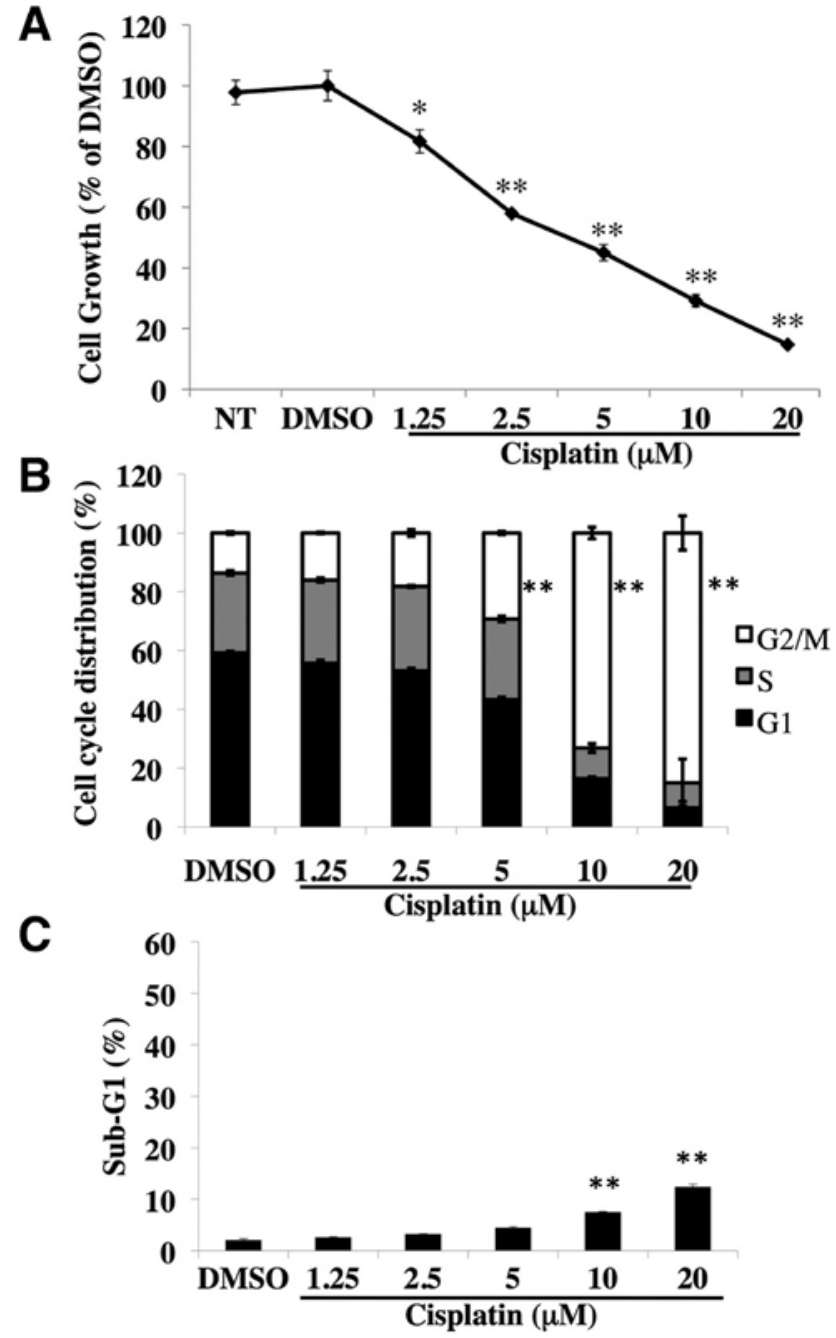

Figure 1. Cisplatin inhibits the cell growth with G2/M-phase arrest. (A) The effect of cisplatin on the growth of SKOV3 cells. SKOV3 cells were treated with DMSO (control) or the indicated concentrations of cisplatin. After incubation for $72 \mathrm{~h}$, viable cells were counted using Cell Counting Kit-8. Columns, means of data $(\mathrm{n}=4)$; bars, $\mathrm{SD} ;{ }^{*} \mathrm{P}<0.05,{ }^{* *} \mathrm{P}<0.01$ relative to the control. (B) Cell cycle analysis of SKOV3 cells treated with cisplatin at the indicated concentrations for $72 \mathrm{~h}$. The DNA contents of the cells were analyzed by flow cytometry. The percentage in each phase of the cell cycle is shown. Columns, means of triplicate data; bars, $\mathrm{SD} ;{ }^{* *} \mathrm{P}<0.01$ relative to the control. (C) The effect of cisplatin on cell cycle progression. SKOV3 cells were treated with cisplatin at the indicated concentrations for $72 \mathrm{~h}$. Apoptosis (sub-G1) was determined using flow cytometry analysis. Columns, means of triplicate data; bars, $\mathrm{SD} ;{ }^{* *} \mathrm{P}<0.01$ relative to the control.

the Student's t-test. Samples were considered significantly different when $\mathrm{P}<0.05$.

\section{Results}

Cisplatin inhibits cell growth with G2/M-phase arrest in ovarian cancer SKOV3 cells. High resistance to cisplatin in many human ovarian cancer cell lines has been reported (20). Here, we investigated the effects of cisplatin on ovarian cancer SKOV3 cells. After treatment with the indicated concentrations of cisplatin for $72 \mathrm{~h}$, cisplatin dose-dependently inhibited the cell growth (Fig. 1A). We then performed cell cycle analysis and measured the sub-G1 population to quantify apoptotic cells. The treatment with cisplatin at $5 \mu \mathrm{M}$ or more 
A

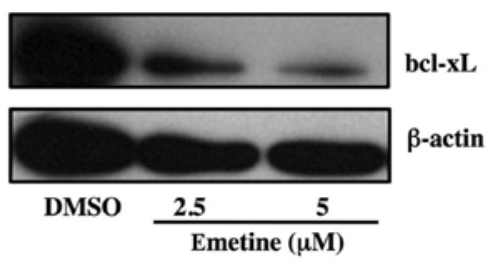

B
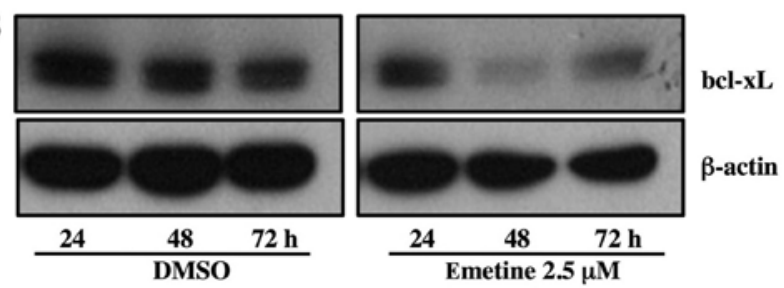

C

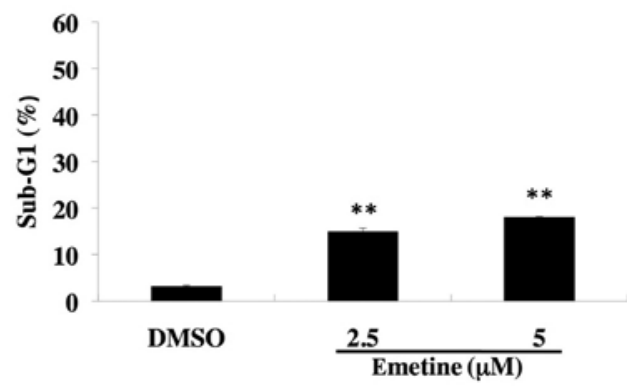

Figure 2. Emetine reduces anti-apoptotic bcl-xL expression with slight induction of apoptosis. (A) The effect of emetine at the indicated concentrations for $72 \mathrm{~h}$ on the expression of bcl-xL, analyzed by western blotting. $\beta$-actin was used as a loading control. (B) Emetine at $2.5 \mu \mathrm{M}$ reduced the bcl-xL protein expression. (C) The effect of emetine on inducing apoptosis. SKOV3 cells were treated with emetine at the indicated concentrations for $72 \mathrm{~h}$. Apoptosis was determined using flow cytometry analysis. Columns, means of triplicate data; bars, $\mathrm{SD} ;{ }^{* *} \mathrm{P}<0.01$ relative to the control. for $72 \mathrm{~h}$ increased the $\mathrm{G} 2 / \mathrm{M}$ phase in a dose-dependent manner (Fig. 1B), but barely induced apoptosis (Fig. 1C). These results clearly show that cisplatin inhibited the growth of human ovarian cancer SKOV3 cells with G2/M-phase arrest.

Emetine reduces anti-apoptotic bcl-xL expression with slight induction of apoptosis. Among anti-apoptotic members, bcl-xL expression is frequently upregulated during carcinogenesis (21), and is associated with resistance to chemotherapeutic agents in malignant tumors of various origins (22-25). In this study, we found that treatment of emetine at 2.5 or $5 \mu \mathrm{M}$ for $72 \mathrm{~h}$ decreased the protein expression of bcl-xL (Fig. 2A) in ovarian cancer SKOV3 cells, whereas treatment of $2.5 \mu \mathrm{M}$ emetine for $24 \mathrm{~h}$ did not reduce the expression of bcl-xL (Fig. 2B). As described, emetine at 2.5 or $5 \mu \mathrm{M}$ effectively downregulated the anti-apoptotic bcl-xL protein expression (Fig. 2A), but it could induce only weak apoptosis (Fig. 2C).

Combination treatment with cisplatin and emetine timedependently induce caspase-dependent apoptosis. We next investigated whether emetine sensitized SKOV3 cells to cisplatin. As shown in Fig. 3A, co-treatment with $20 \mu \mathrm{M}$ cisplatin and 2.5 or $5 \mu \mathrm{M}$ emetine significantly induced apoptosis in SKOV3 cells. The time-dependence of apoptosis induced by the combination of cisplatin and emetine is shown in Fig. 3B. Combined treatment for $24 \mathrm{~h}$ did not induce increased apoptosis. However, co-treatment with cisplatin and emetine for 48 and $72 \mathrm{~h}$ apparently increased it. These results are in accordance with the data shown in Fig. $2 \mathrm{~B}$ that emetine at $2.5 \mu \mathrm{M}$ for $24 \mathrm{~h}$ did not reduce the expression of bcl-xL, but it was decreased by the treatment for 48 and $72 \mathrm{~h}$. To investi-
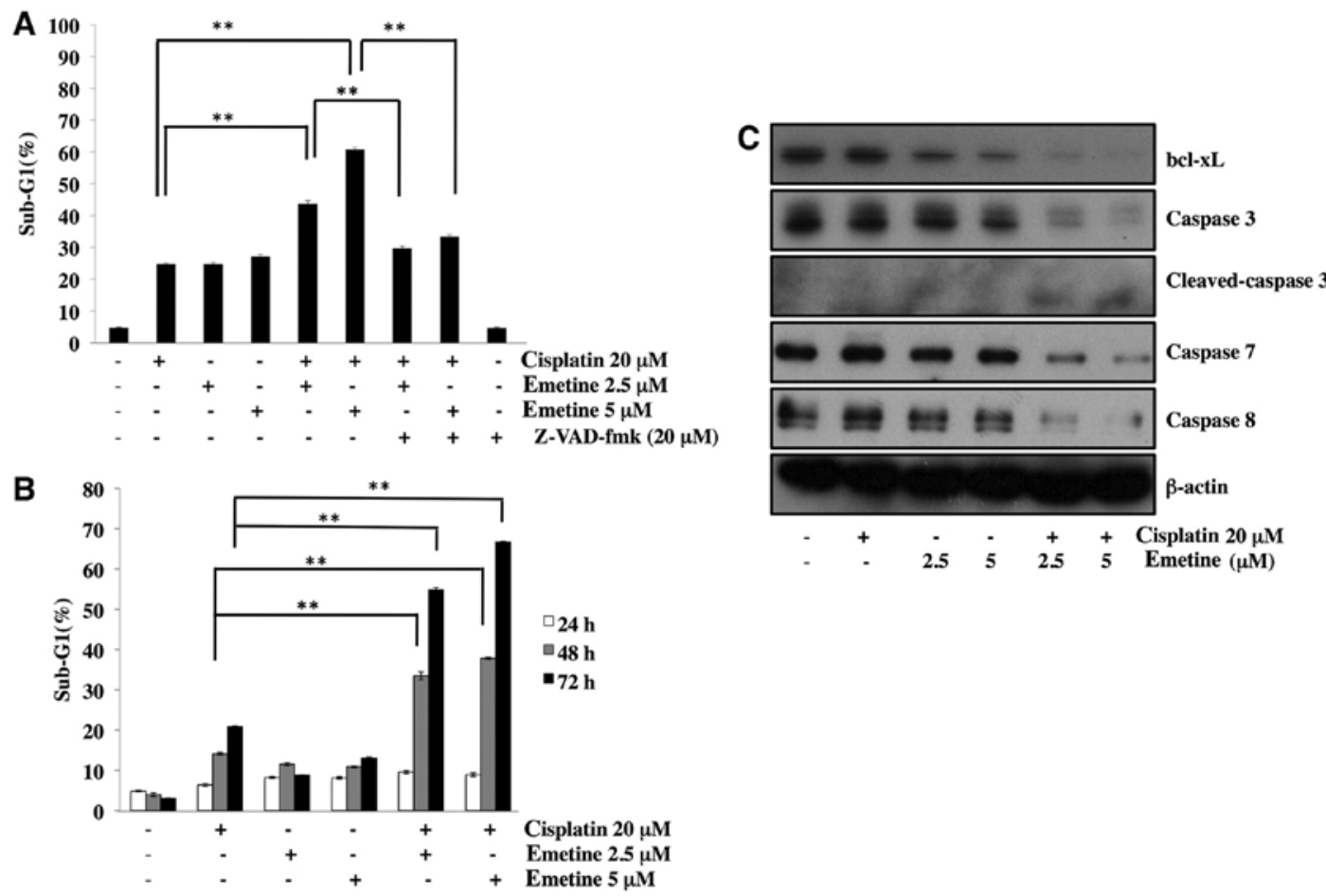

Figure 3. Combination treatment with cisplatin and emetine time-dependently induces caspase-dependent apoptosis. (A) SKOV3 cells were treated with $20 \mu \mathrm{M}$ cisplatin and/or 2.5 or $5 \mu \mathrm{M}$ emetine with or without the pan-caspase inhibitor zVAD-fmk $(20 \mu \mathrm{M})$ for $72 \mathrm{~h}$. The sub-G1 population was analyzed by flow cytometry. Columns, means of triplicate data; bars, SD; ${ }^{* *} \mathrm{P}<0.01$. (B) SKOV3 cells were treated with $20 \mu \mathrm{M}$ cisplatin and/or $2.5 \mu \mathrm{M}$ emetine for 24,48 and $72 \mathrm{~h}$. The sub-G1 population was analyzed by flow cytometry. Columns, means of triplicate data; bars, SD; * $\mathrm{P}<0.01$. (C) Western blotting of bcl-xL, caspase-3, -7 and -8 . SKOV3 cells were treated with $20 \mu \mathrm{M}$ cisplatin and/or 2.5 or $5 \mu \mathrm{M}$ emetine for $72 \mathrm{~h}$. $\beta$-actin is shown as a loading control. 
A
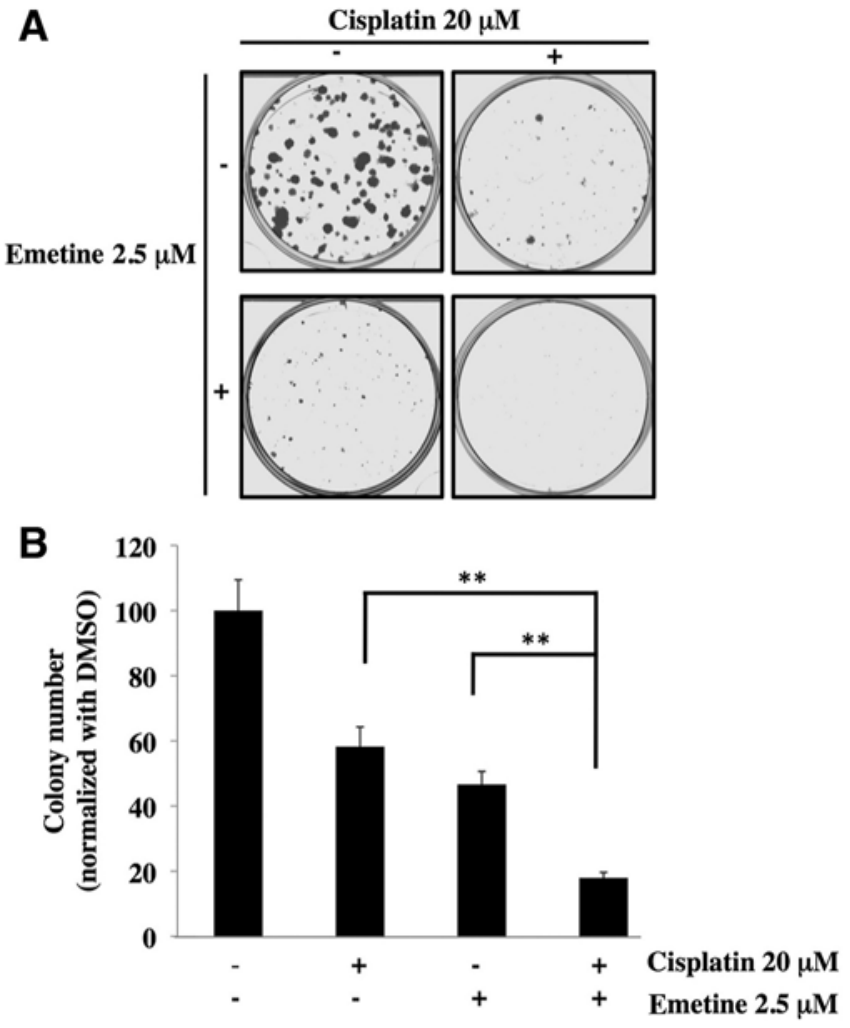

Figure 4. Combination treatment with cisplatin and emetine suppresses colony formation. (A) Images of the colonies. SKOV3 cells were treated with $20 \mu \mathrm{M}$ cisplatin, $2.5 \mu \mathrm{M}$ emetine or a combination of both for $48 \mathrm{~h}$. Then, the cells were washed out and incubated in growth medium for 10 days. (B) The quantitative result of colonies. The data are presented as a percentage compared with the control DMSO. Columns, means of triplicate data; bars, SD; ${ }^{* *} \mathrm{P}<0.01$

gate whether apoptosis was caspase-dependent, we analyzed the effect of a pan-caspase inhibitor, zVAD-fmk. Apoptosis induced by the combination was partially inhibited by this inhibitor (Fig. 3A). Furthermore, the combination clearly enhanced the activation of caspases with reduction of bcl-xL expression (Fig. 3C).

Combination treatment with cisplatin and emetine decreases colony formation. We then performed a colony formation assay to investigate the effect of the combined treatment with cisplatin and emetine. Cisplatin at $20 \mu \mathrm{M}$ or emetine at $2.5 \mu \mathrm{M}$ reduced the colony number to 58 and $47 \%$, respectively, whereas combined treatment with $20 \mu \mathrm{M}$ cisplatin and $2.5 \mu \mathrm{M}$ emetine markedly decreased it to $17 \%$ (Fig. 4). These results indicate that emetine could sensitize SKOV3 cells to cisplatin.

Downregulation of bcl-xL enhances apoptosis induced by cisplatin. To confirm the contribution of the downregulation of bcl-xL by emetine to the enhancement of apoptosis induced by cisplatin, we performed the knockdown of bcl-xL by siRNA. As shown in Fig. 5A, knockdown of bcl-xL markedly enhanced the apoptosis by cisplatin in SKOV3 cells. Moreover, the knockdown of bcl-xL caused the cleavage of caspases (Fig. 5B). These results suggest that the downregulation of bcl-xL expression contributed to the enhancement of apoptosis by the combination of cisplatin and emetine.
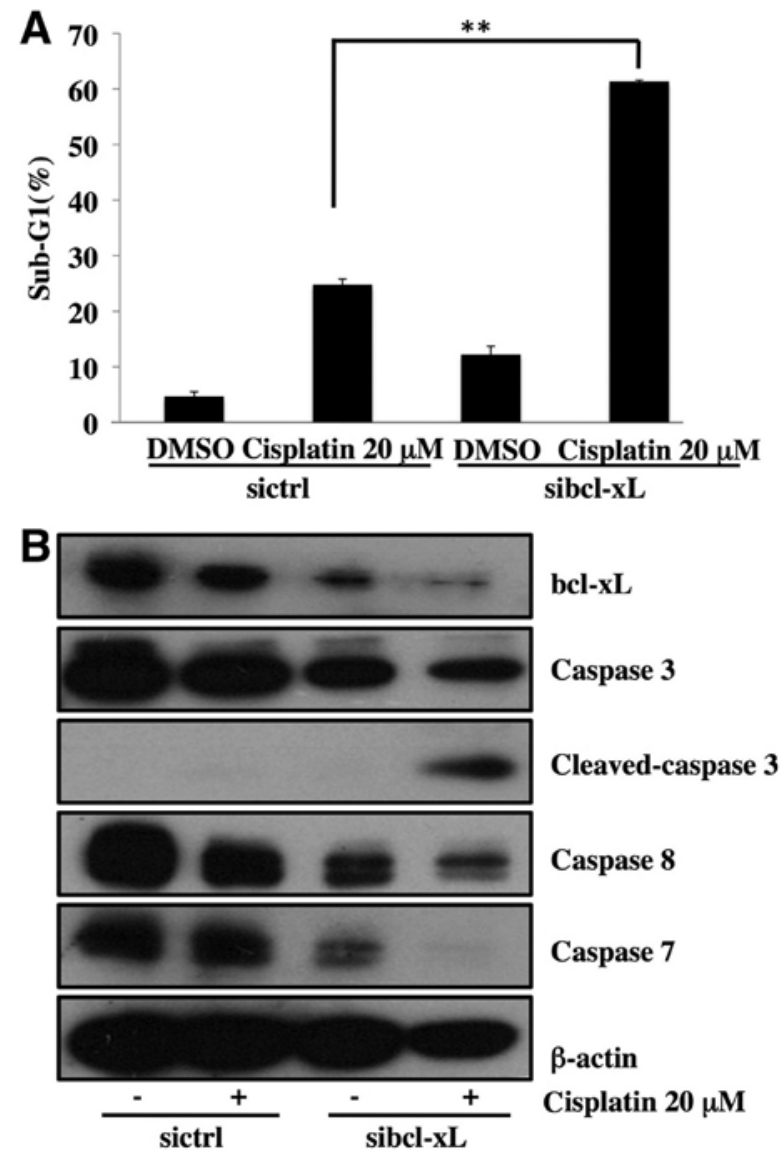

Figure 5. Combination treatment with cisplatin and sibcl-xL induces caspasedependent apoptosis. SKOV3 cells were transfected with $100 \mathrm{nM}$ sibcl-xL or sicontrol (sictrl). Twenty-four hours after the transfection, the cells were treated with or without $20 \mu \mathrm{M}$ cisplatin for $72 \mathrm{~h}$. (A) The sub-G1 population was analyzed by flow cytometry. Columns, means of triplicate data; bars, $\mathrm{SD} ;{ }^{* *} \mathrm{P}<0.01$. (B) Western blotting of bcl-xL, caspase-3, -7 , and $-8 . \beta$-actin is shown as a loading control.

\section{Discussion}

One of the major goals of cancer chemotherapy is to induce apoptosis in tumor cells by exposure to antitumor agents. Although cisplatin is a potent inducer of apoptosis in ovarian cancer cells, the resistant tumor cells have been found to fail to undergo apoptosis upon treatment with cisplatin (26-28). We demonstrated here that cisplatin inhibited cell growth with G2/M-phase arrest but slightly increased apoptosis in ovarian carcinoma SKOV3 cells (Fig. 1). To enhance the sensitivity, the identification of new agents that can sensitize SKOV3 cells to apoptosis induced by cisplatin appears as a major challenge. In the present study, we found that co-treatment of cisplatin and emetine remarkably induced apoptosis and reduced colony formation of SKOV3 cells (Figs. 3 and 4). It is interesting that emetine, which was used as an anti-amoebiasis drug 100 years ago, could sensitize SKOV3 cells to apoptosis induced by cisplatin.

There are several reports describing that bcl-xL expression contributed to chemotherapy resistance in ovarian carcinoma by inhibiting chemotherapy-induced apoptosis (29-31). Therefore, downregulation of bcl-xL is reasonable for sensitizing ovarian cancer cells to chemotherapy. We found 
that emetine could reduce the expression of bcl-xL in SKOV3 cells for the first time (Fig. 2A and B). However, the reduction of bcl-xL expression by emetine alone was insufficient to enhance apoptosis in SKOV3 cells (Fig. 2C). We speculated that emetine might sensitize SKOV3 cells to apoptosis induced by cisplatin through the downregulation of bcl-xL. The present experiments showed that single treatment of cisplatin did not reduce the expression of bcl-xL, but co-treatment of cisplatin and emetine did, which led to the induction of apoptosis with activated caspases (Fig. 3). Moreover, the knockdown of bcl-xL with siRNA enhanced the sensitivity to cisplatin of SKOV3 cells (Fig. 5), which was consistent with the results for the combination of cisplatin and emetine (Figs. 3 and 4). Taken together, these studies indicate that emetine as a downregulator of bcl-xL might be a promising agent to sensitize ovarian cancer cells to cisplatin.

Previously it was reported that emetine sensitizes leukemic cancer cells and bladder cancer cells to chemotherapy $(17,18)$. However, the precise molecular mechanisms by which emetine improves the sensitivity of cancer cells remain unclear. Recent studies reported that emetine enhanced the sensitivity of pancreatic cancer cells to TRAIL-induced apoptosis by downregulating mcl-1 protein (32); the authors suggested that emetine was highly specific to TRAIL since it did not have any effect on other cell death-inducing agents, such as thapsigargin, daunorubicin and paclitaxel (32). However, our study, we found that emetine sensitized ovarian carcinoma cells to cisplatin through downregulation of bcl-xL. These studies suggest that the functions of emetine as a sensitizer for chemotherapeutic agents might vary depending on the cancer cell type. Therefore, the mechanisms for emetine's involvement in the enhancement of the sensitivity of cancer cells require further investigation.

In conclusion, we found that emetine sensitizes ovarian carcinoma SKOV3 cells, which were initially resistant to cisplatin-induced apoptosis. We demonstrated, for the first time, that the downregulation of bcl-xL by emetine is a key factor in sensitizing SKOV3 cells to cisplatin. The combination of cisplatin with emetine might be worth developing as a possible treatment for ovarian cancer. Furthermore, the use of emetine in combination with other chemotherapeutic agents for other cancer cells remains an interesting topic for further studies.

\section{Acknowledegements}

This study was supported in part by the Ministry of Education, Culture, Sports, Science and Technology of Japan.

\section{References}

1. Jemal A, Bray F, Center MM, Ferlay J, Ward E and Forman D: Global cancer statistics. CA Cancer J Clin 61: 69-90, 2011.

2. Ali AY, Farrand L, Kim JY, Byun S, Suh JY, Lee HJ and Tsang BK: Molecular determinants of ovarian cancer chemoresistance: new insights into an old conundrum. Ann NY Acad Sci 1271: 58-67, 2012

3. McGuire WP III and Markman M: Primary ovarian cancer chemotherapy: current standards of care. Br J Cancer 89: S3-S8, 2003.

4. Grollman AP: Inhibitors of protein biosynthesis. V. Effects of emetine on protein and nucleic acid biosynthesis in HeLa cells. J Biol Chem 243: 4089-4094, 1968.
5. Lambert AC: The treatment of amoebic dysentery with emetine and bismuth iodide. Br Med J 1: 116-118, 1918.

6. Lewisohn R: Action of emetine on malignant tumors. JAMA 70: 9-10, 1918.

7. Panettiere F and Coltman CA Jr: Experience with emetine hydrochloride (NSC 33669) as an antitumor agent. Cancer 27: 835-841, 1971.

8. Mastrangelo MJ, Grage TB, Bellet RE and Weiss AJ: A phase I study of emetine hydrochloride (NSC 33669) in solid tumors. Cancer 31: 1170-1175, 1973.

9. Siddiqui S, Firat D and Olshin S: Phase II study of emetine (NSC-33669) in the treatment of solid tumors. Cancer Chemother Rep 57: 423-428, 1973.

10. Kane RC, Cohen MH, Broder LE, Bull MI, Creaven PJ and Fossieck BE Jr: Phase I-II evaluation of emetine (NSC-33669) in the treatment of epidermoid bronchogenic carcinoma. Cancer Chemother Rep 59: 1171-1172, 1975.

11. Bicknell GR, Snowden RT and Cohen GM: Formation of high molecular mass DNA fragments is a marker of apoptosis in the human leukaemic cell line, U937. J Cell Sci 107: 2483-2489, 1994.

12. Möller M, Weiss J and Wink M: Reduction of cytotoxicity of the alkaloid emetine through P-glycoprotein (MDR1/ABCB1) in human Caco-2 cells and leukemia cell lines. Planta Med 72: 1121-1126, 2006

13. Möller M and Wink M: Characteristics of apoptosis induction by the alkaloid emetine in human tumour cell lines. Planta Med 73: 1389-1396, 2007.

14. Rosenkranz V and Wink M: Alkaloids induce programmed cell death in bloodstream forms of trypanosomes (Trypanosoma b. brucei). Molecules 13: 2462-2473, 2008.

15. Watanabe N, Iwamoto T, Dickinson DA, Iles KE and Forman HJ: Activation of the mitochondrial caspase cascade in the absence of protein synthesis does not require c-Jun N-terminal kinase. Arch Biochem Biophys 405: 231-240, 2002.

16. Boon-Unge K, Yu Q, Zou T, Zhou A, Govitrapong P and Zhou J: Emetine regulates the alternative splicing of Bcl-x through a protein phosphatase 1-dependent mechanism. Chem Biol 14: 1386-1392, 2007.

17. Möller M, Herzer K, Wenger T, Herr I and Wink M: The alkaloid emetine as a promising agent for the induction and enhancement of drug-induced apoptosis in leukemia cells. Oncol Rep 18: 737-744, 2007.

18. Foreman KE, Jesse JN III, Kuo PC and Gupta GN: Emetine dihydrochloride: a novel therapy for bladder cancer. J Urol 191: 502-509, 2014

19. Qian J, Zou Y, Rahman JS, Lu B and Massion PP: Synergy between phosphatidylinositol 3-kinase/Akt pathway and Bcl-xL in the control of apoptosis in adenocarcinoma cells of the lung. Mol Cancer Ther 8: 101-109, 2009.

20. Godwin AK, Meister A, O'Dwyer PJ, Huang CS, Hamilton TC and Anderson ME: High resistance to cisplatin in human ovarian cancer cell lines is associated with marked increase of glutathione synthesis. Proc Natl Acad Sci USA 89: 3070-3074, 1992.

21. Kirkin V, Joos S and Zörnig M: The role of Bcl-2 family members in tumorigenesis. Biochim Biophys Acta 1644: 229-249, 2004

22. Lebedeva I, Rando R, Ojwang J, Cossum P and Stein CA: Bcl-xL in prostate cancer cells: effects of overexpression and downregulation on chemosensitivity. Cancer Res 60: 6052-6060, 2000.

23. Agarwal R and Kaye SB: Ovarian cancer: strategies for overcoming resistance to chemotherapy. Nat Rev Cancer 3: 502-516, 2003.

24. Sasazawa Y, Futamura Y, Tashiro E and Imoto M: Vacuolar $\mathrm{H}^{+}$-ATPase inhibitors overcome Bcl-xL-mediated chemoresistance through restoration of a caspase-independent apoptotic pathway. Cancer Sci 100: 1460-1467, 2009.

25. Lee SJ,Park HJ, Kim YH, et al: Inhibition of Bcl-xL by ABT-737 enhances chemotherapy sensitivity in neurofibromatosis type 1-associated malignant peripheral nerve sheath tumor cells. Int J Mol Med 30: 443-450, 2012.

26. Fajac A, Da Silva J, Ahomadegbe JC, Rateau JG, Bernaudin JF, Riou $\mathrm{G}$ and Bénard $\mathrm{J}$ : Cisplatin-induced apoptosis and p53 gene status in a cisplatin-resistant human ovarian carcinoma cell line. Int J Cancer 68: 67-74, 1996.

27. Henkels KM and Turchi JJ: Induction of apoptosis in cisplatinsensitive and -resistant human ovarian cancer cell lines. Cancer Res 57: 4488-4492, 1997. 
28. Singh M, Chaudhry P, Fabi F and Asselin E: Cisplatin-induced caspase activation mediates PTEN cleavage in ovarian cancer cells: a potential mechanism of chemoresistance. BMC Cancer 13: 233, 2013.

29. Liu JR, Fletcher B, Page C, Hu C, Nunez G and Baker V: Bcl-xL is expressed in ovarian carcinoma and modulates chemotherapyinduced apoptosis. Gynecol Oncol 70: 398-403, 1998.

30. Williams J, Lucas PC, Griffith KA, Choi M, Fogoros S, Hu YY and Liu JR: Expression of Bcl-xL in ovarian carcinoma is associated with chemoresistance and recurrent disease. Gynecol Oncol 96: 287-295, 2005.
31. Dodier $\mathrm{P}$ and Piché $\mathrm{A}: \mathrm{Bcl}-\mathrm{X}(\mathrm{L})$ is functionally non-equivalent for the regulation of growth and survival in human ovarian cancer cells. Gynecol Oncol 100: 254-263, 2006.

32. Han Y, Park S, Kinyua AW, Andera L, Kim KW and Kim I: Emetine enhances the tumor necrosis factor-related apoptosisinducing ligand-induced apoptosis of pancreatic cancer cells by downregulation of myeloid cell leukemia sequence-1 protein. Oncol Rep 31: 456-462, 2014 